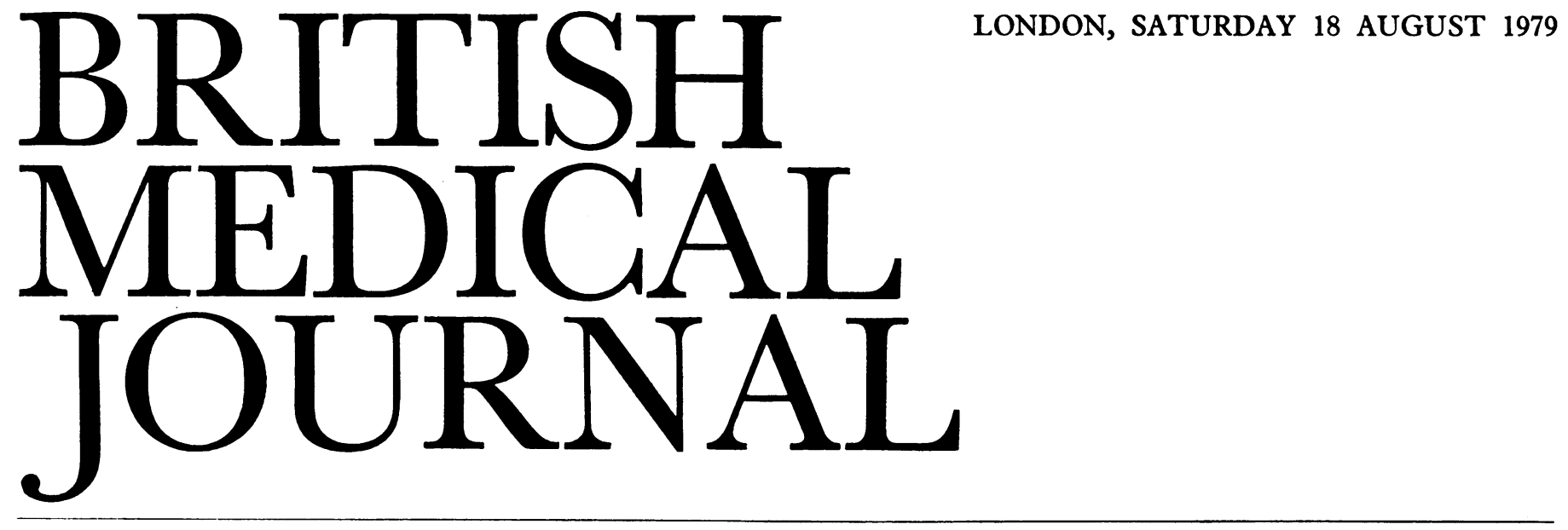

\title{
Induction of labour
}

Five years ago induction of labour was the subject of considerable debate, and there was wide concern over the high incidence in some units. ${ }^{1}$ Induction for social or medical convenience was specially criticised, and in some measure there was a reaction among obstetricians against the procedure. $^{2-5}$ Further studies and new techniques have now led to a renewed interest in this controversial issue-but with greater emphasis placed on a proper understanding of the physiological processes that initiate and maintain labour. ${ }^{6}$

One important development has been the use of prostaglandins to "ripen" the unfavourable cervix and even to induce labour. In $B M \mathcal{F} 14$ July ( $\mathrm{p}$ 108) Shepherd and his colleagues give an account of induction of labour in Queen Charlotte's Maternity Hospital using prostaglandin $E_{2}$ vaginal pessaries. Their experience with 500 consecutive cases encourages them to claim that this is a simple method of induction that may safely be used in most obstetric units in Britain. In time there will be other reports from other units, and with larger numbers we shall be able to make a balanced judgment on the safety and effectiveness of the Queen Charlotte's programme. Confirmation would be reassuring that sustained hypertonic uterine activity can be avoided by careful selection of patients, and we need to know much more about the effects of prostaglandin vaginal pessaries in patients with a scar in the lower uterine segment. Nevertheless, the Queen Charlotte's regimen has many attractive features: it is simple, puts the patient to little inconvenience, is particularly helpful in those cases where the cervix is unfavourable for induction, and reduces the need for amniotomy and intravenous infusion.

From Dublin, $\mathrm{Clinch}^{7}$ has reported the results of a more conventional method of induction-rupture of the forewaters together with oxytocin infusion. In the six years 1972 to 1977 at the Coombe Lying-In Hospital $35 \%$ of patients were induced in this way, mostly on account of postmaturity or pre-eclampsia. Induced women had a higher percentage of normal vaginal delivery, a lower perinatal mortality rate, and a lower caesarean section rate than those whose labours began spontaneously. Clinch offers several reasons for these favourable results. He and his colleagues paid special attention to gestational age and largely avoided the risk of unsuspected prematurity-there has to be a very strong indication for induction before 40 weeks. Since 1974 no baby has died from respiratory distress after induction of labour. Furthermore, the Dublin regimen is cautious in its use of oxytocin, four hours elapsing before the dosage achieved reaches three times the starting dose.

In 1966-75 the rate of induction of labour in the Glasgow Royal Maternity Hospital increased from 16.3 to $35.6 \%$ of all births. Part of the drop in perinatal mortality from 33 to 22 per 1000 has been attributed to that increased use of induction. ${ }^{8}$ The most striking finding was the sharp decrease in the number of perinatal deaths classified as "mature, cause unknown." McNay et $a l^{8}$ argue that their policy of avoiding prolonged pregnancy by timely induction of labour has brought this welcome fall in the number of unexplained deaths beyond term. They found no evidence that the increased induction rate led to more deaths from trauma or unsuspected prematurity.

Other studies, however, have found no advantage in high induction rates. ${ }^{9-11}$ In Cardiff, where induction of labour was practised much more frequently by one of two obstetric teams, no substantial advantage or disadvantage could be shown from the more active approach. ${ }^{12}$ An Oxford study ${ }^{13}$ compared a group of women who had labour induced with a closely matched group who went into labour spontaneously. In neither group was there any obstetric or medical abnormality. Women in the induced group received more intervention during labour and were more likely to have an operative delivery, and more of their babies needed resuscitation by intubation. The authors were unable to give a convincing explanation for these differences, but they found that one group of induced women, who were mostly beyond term, had uncomplicated labours and delivered without intervention. The Oxford team suggested that this group of women, already close to spontaneous labour, is protected from the complications of induction by the physiological changes that precede the onset of labour.

These contrary views on the safety and value of induction of labour are difficult to reconcile. To some extent different methods of classifying perinatal deaths could account for the disagreement over the reduction of deaths, particularly at term and beyond. The evidence from Glasgow ${ }^{8}$ is persuasive and is based on sound physiological principles. Others have emphasised the importance of postmaturity as a causal factor in perinatal death. ${ }^{14} 15$

The debate continues, but it should alter in character in the light of new studies and developments in technique. 
Certain trends are noticeable. Induction for purely social or medical convenience is recognised to be bad practice and is probably less used now than it was five years ago. Obstetricians are more aware of the need to pay careful attention to the gestational age and so avoid the embarrassment and the dangers of an unexpected premature delivery. Interest is passing increasingly to non-invasive techniques, which are more comfortable for the patients and less likely to bring complications. Finally, there is no agreement about an acceptable rate of induction, but McNay et al ${ }^{8}$ are very likely right when they suggest that the optimum induction rate will vary from area to area depending on local medical and obstetric problems.

1 Lancet, 1974, 2, 1183.

2 O'Herlihy, C, and MacDonald, D, Lancet, 1975, 2, 126.

3 Bonnar, J, British Medical fournal, 1976, 1, 651.

4 Chalmers, I, et al, British Medical fournal, 1976, 1, 735.

5 Leeson, J, and Smith, A, British Medical fournal, 1977, 1, 707.

6 Beazley, J M, American fournal of Obstetrics and Gynecology, 1979, 133, 723.

${ }^{7}$ Clinch, J, British fournal of Obstetrics and Gynaecology, 1979, 86, 340.

${ }^{8}$ McNay, M B, et al, British Medical fournal, 1977, 1, 347.

9 O'Driscoll, K, Carroll, C J, Coughlan, M, British Medical fournal, 1975, 4, 727.

10 Chalmers, I, et al, British Medical fournal, 1976, 1, 735.

11 Chalmers, I, Lawson, J G, Turnbull, A C, British Journal of Obstetrics and Gynaecology, 1976, 83, 930.

12 Chalmers, I, Lawson, J G, Turnbull, A C, British fournal of Obstetrics and Gynaecology, 1976, 83, 921.

13 Yudkin, P, et al, British Fournal of Obstetrics and Gynatcology, 1979, 86, 257.

14 Walker, J, Fournal of Obstetrics and Gynaecology of the British Empire, 1954, 61, 162.

15 Butler, N R, and Bonham, D G, Perinatal Mortality. Edinburgh, Livingstone, 1963.

\section{Iatrogenic collapse}

Any doctor carrying out the simplest physical procedurestitching a wound, sigmoidoscopy, or even venepuncturemust accept that there is a risk that the patient may collapse. Fortunately such occurrences are relatively rare, often predictable, and nearly always treatable.

The two main types of iatrogenic collapse are those due to neurogenic shock and to anaphylactic shock. Neurogenic shock in its simplest form (a vasovagal faint) may result from the combination of a hot room and fear of what is about to be done. Its distinguishing features are bradycardia and the brevity of the episode. A more intense neurogenic reaction may result from instrumentation of the urogenital system. If a patient with acute retention of urine is catheterised and the tension relieved rapidly he may collapse with a reflex vasodilatation of the peripheral vascular system. A similar response may result from dilatation of the cervix in procedures such as the insertion of an intrauterine contraceptive device (IUCD). In the last 10 years some three million IUCDs have been inserted in hospitals, family planning clinics, and general practitioners' surgeries. While the incidence of vasovagal responses seems to be very low the possibility has caused some concern among doctors, and the problem has recently been examined ${ }^{1}$ by the joint committee on contraception of the Royal College of Obstetricians and Gynaecologists and the Royal College of General Practitioners. In the committee's view every doctor who inserts IUCDs should have had adequate training in modern methods of resuscitation. Its report emphasises that the risk of an untoward response may be minimised by reducing the patient's nervous tension before and during the procedure; a bedside manner is part of the science as well as of the art of medicine. At the earliest sign of a vasovagal response the procedure should be abandoned or the partly inserted device removed. The doctor should immediately ensure that the patient is kept flat, with legs raised, head tilted, and airway patent. An artificial airway (such as the Brook) should be to hand, and oxygen and a bag and mask may be used if needed. Persistent bradycardia may respond to intravenous atropine $0.6 \mathrm{mg}$, but in most cases simple postural adjustment is all that is necessary. The patient should be turned into the recovery position as soon as possible to prevent complications such as inhalation of vomit. In the unlikely event that the patient fails to regain consciousness, cardiopulmonary support should be provided and the patient transferred by ambulance to the nearest accident and emergency department or intensive care unit.

The second main cause of sudden iatrogenic collapse, anaphylactic shock after an injection, is also rare, and its occurrence can often be anticipated. A generalised reaction is more likely to develop in patients who suffer from asthma, hay fever, or other allergies. ${ }^{2}$ The drugs usually responsible are antisera, vaccines, or antibiotics. Second and repeat injections after an interval of 10 days or more carry an increased risk. Symptoms may occur within seconds or up to 30 minutes after the injection, and in general the more rapid the response the more severe the reaction.

The clinical features of anaphylactic collapse include tingling of the scalp and tongue, headache, dyspnoea, cyanosis or pallor, hypotension, nausea, vomiting, diarrhoea, and urticaria. Angioneurotic oedema affecting the face and throat is a rare complication. These clinical features may occur in any combination and order. The standard treatment is $1: 1000$ adrenaline 0.2 to $0.5 \mathrm{ml}$ given subcutaneously at a rate of $0.1 \mathrm{ml}$ a minute. In addition, the patient may be given an antihistamine, such as chlorpheniramine $10 \mathrm{mg}$ by intravenous or intramuscular injection. Intravenous hydrocortisone sodium succinate $100-300 \mathrm{mg}$ is particularly effective in treating angioneurotic oedema. ${ }^{3}$ Cardiorespiratory support may also be necessary.

What precautions can be taken to minimise untoward reactions to minor procedures? Any patient known to be at risk should be observed for 30 minutes after an injection. At hand should be a Brook airway, adrenaline, chlorpheniramine, hydrocortisone, and the means for giving these drugs; and simple treatment should be started the moment the emergency is recognised.

${ }^{1}$ Joint Committee on Contraception statement. London, Royal College of Obstetricians and Gynaecologists, 1979.

${ }^{2}$ Ledingham, I McA, and McAllister, T A, ed, Conference on Shock. London, Henry Kimpton, 1972.

s British National Formulary, 1976-8, p 72. London, British Medical Association and Pharmaceutical Press.

\section{Epidemic hysteria}

A recent report ${ }^{1}$ from Jamaica is a reminder that school outbreaks of epidemic hysteria occur in all cultures and climates. One Wednesday in November last year 62 pupils at a primary day school in Kingston were taken ill with abdominal pain. A few had vomiting and diarrhoea; some fainted; and some were seen to be overbreathing. Sixteen of the children were taken to hospital, and five were admitted, but all improved 